\title{
Antioxidant and antibacterial activity of ethanolic extract of safflower with contrasting
}

\section{seed coat colors}

\author{
Basaki Tayebeh $^{1}$, Karami Soraya ${ }^{1 *}$, Amin Mousavi Khaneghah ${ }^{2}$ \\ ${ }^{1}$ Department of Agricultural Science, Payame Noor University, Tehran, Iran; ${ }^{2}$ Department of Food Science and Nutrition, \\ Faculty of Food Engineering, University of Campinas (UNICAMP), Campinas, São Paulo, Brazil
}

*Corresponding author: Karami Soraya, Department of Agricultural Science, Payame Noor University, Tehran, Iran. Email: karamisoraya@gmail.com

Submitted: 19 December 2020; Accepted: 21 March 2021; Published: 2 June 2021

(c) 2021 Codon Publications

OPEN ACCESS @) (1) ORIGINAL ARTICLE

\begin{abstract}
The present study aimed to investigate total flavonoid (TFC), cyanidin-3-glucoside (Cyd-3-glu) content, and antioxidant and antibacterial activities of ethanolic seed coat extract of two safflower genotypes (genotype C111 and A82) with contrasting seed coat colors. Despite the absence of Cyd-3-glu in seed coat extracts of white-seeded genotype C111 versus black-seeded genotype A82 and equal TFC index between the two genotypes, there was no significant difference in their antioxidant activity. Also, the ethanolic extract has growth inhibitory properties in pathogenic bacteria. It seems that differences in type and level of secondary metabolites of the seed coat with different color patterns can result in the ethanolic extract's antioxidant activity. In addition, the results confirmed that seed coat color has not effect on the level (or severity) of the antibacterial properties of ethanolic seed coat extract.
\end{abstract}

Keywords: antibacterial activity; antioxidant activity; safflower; seed coat color

\section{Introduction}

Plants are always considered as one of the most important foods and medicine sources (Brizzolari et al., 2019; Palacios-Rojas et al., 2020). Statistics show that the effective compound of more than $50 \%$ of the medicine and a significant part of the food industry's ingredients are of plant origin (Mazzei et al., 2020). Therefore, there is a growing intention to use plants in the pharmaceutical and food industries (Rezig et al., 2019). The safflower (Carthamus tinctorius L.) is one of the first cultivated plants as a natural coloring and flavoring agent in food by using the florets (Karami et al., 2017a; Zuniga-Salcedo et al., 2019). Today, the primary purpose of cultivating this plant is to produce seeds (Nimrouzi et al., 2020). Safflower seeds are rich in unsaturated fatty acids such as linoleic and oleic acids, biologically active compounds, and phenolic and flavonoid compounds with antioxidant properties (Sabzalian et al., 2008). Therefore, these seeds are the main focus of many research types as pharmaceuticals and food additives. Safflower has high antibacterial and antioxidant activity due to its wide range of compounds with the phenolic group (Güner et al., 2020). Previous studies have shown that safflower water extract has antibacterial properties against various bacteria such as Bacillus subtilis, Bacillus cereus, and Bacillus mycoides (Turgumbayeva et al., 2020). Numerous studies have also reported a positive effect of polyphenolic compounds, such as flavonoids, in safflower in clearing the free radicals' body (Choi et al., 2018).

Many environmental and nonenvironmental factors such as genetics, physical appearance, physiological conditions, and extraction methods affect the quantity and quality of the polyphenolic compounds extracted from plants (Fang et al., 2011). Seed color as one of the physical 
appearance factors can affect seed polyphenolic extract (Kanu, 2011). Moreover, the relationship between the seed color and the phenolic and flavonoid content of seed extract is proven in many studies (Kanu, 2011; Karami et al., 2018; Sabzalian et al., 2008; Shen et al., 2009; Thaddi and Nallamilli, 2014). For instance, the amount of phenolic and anthocyanin compounds in the colored seed is higher than in white beans. Therefore, the colored bean has higher antioxidant activity (Akond et al., 2011).

There are different color patterns of the safflower's seed coat (Karami et al., 2017b). However, the color of the cultivated safflower is found to be white or cream (Karami et al., 2018). Sabzalian et al. (2010) introduced a novel breeding line with black seed coats (A82). On the other hand, the genotype A 82 has been suggested as a preferable and superior genotype for cultivation in areas infested by the safflower fly (Kanu, 2011). Also, some evidence implies that seed color and the chemical compounds of seed color are involved in reducing insect or pest injuries (Sabzalian et al., 2010). Our previous study found that the concentration of flavonoid compounds detected in the black-seeded genotype's methanolic extract (A82) was significantly lower than the white/brown seeded safflower genotypes. Conversely, antioxidant activity was higher in black-seeded genotypes than in white-seed ones (Karami et al., 2018). It has been shown that the type of solvent that was used for the extraction plays an important role in determining the polyphenol and flavonoid content extracted from plants and subsequently their antioxidant and antibacterial effects (Skowyra et al., 2014). Despite our relatively comprehensive previous study on the identification and determination of secondary metabolites in Carthamus species with pigmented and nonpigmented seeds, no reports are available concerning the effect of seed color and extraction solvents on secondary metabolites and their clinical properties. Thus, the present study aimed to investigate total flavonoid (TFC), cyanidin-3-glucoside (Cyd-3-glu) content, and also antioxidant and antibacterial activities of ethanolic seed coat extract of two safflower genotypes (genotypes C111 and A82) with contrasting seed coat colors.

\section{Materials and Methods}

\section{Plant material}

For this study, two accessions of safflower were selected. One accession belonged to the cultivated species with white seed coat color (Iranian breeding lines, C111), and one novel safflower breeding line (A82) with black seed coats obtained via interspecific hybridization of C111, as the female parent, and a black-seeded genotype of a wild safflower species (C. oxyacanthus) following backcrossing and selfing programs (personal collection:

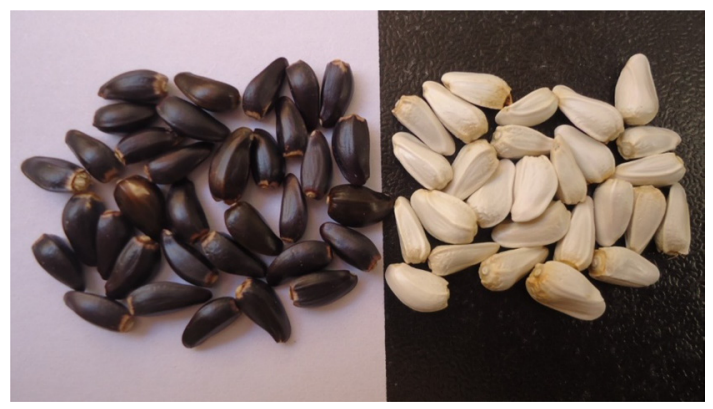

Figure 1. Black-seeded safflower genotype A82 (left); white-seeded safflower genotype C111 (right).

Assoc. Prof. M. R. Sabzalian). All of the plant materials were identified by Assoc. Prof. M. R. Sabzalian, and the specimens were deposited with the Herbarium of Isfahan University of Technology, Isfahan, Iran. Harvested seeds at the maturity stage of plants were de-coated, and then seed coats were used in experiments (Figure 1).

\section{Preparation of ethanolic extract}

To prepare an ethanolic extract from the seed coat, the modified method of Yu et al. (2013) was used. For this purpose, the seed coat of the genotypes was dried at $40^{\circ} \mathrm{C}$ for $24 \mathrm{~h}$, using a ventilated oven, up to a moisture content of 5\%, and was then ground using a grinder (IKA M20, IKA, Staufen, Germany). Then, seed coat powder samples $(5 \mathrm{~g})$ were extracted with $100 \mathrm{~mL}$ of $80 \%$ ethanol (v:v) and shaken by using an orbital shaker (KS260 basic, IKA, Germany) (90 rpm, $24^{\circ} \mathrm{C}$, and $24 \mathrm{~h}$ ), and the extract was filtered through Whatman No. 3 filter paper to remove the solid debris, with each filtration repeated two times. Afterward, the resultant extracts were evaporated to remove ethanol and vacuum-dried under room temperature and were redissolved in ethanol (80\%).

\section{Total flavonoid content (TFC)}

TFC of all the samples was determined according to the method described by Tohidi et al. (2017). Briefly, a volume of $125 \mu \mathrm{L}$ of the filtered ethanolic extract of seed coat was mixed with $75 \mu \mathrm{L}$ of a sodium nitrate solution $\left(5 \% \mathrm{NaNO}_{2}\right)$. The mixture was allowed to remain for 6 min, and subsequently, $150 \mu \mathrm{L}$ of aluminum Chloride $\left(10 \% \mathrm{AlCl}_{3}\right)$ was added. Finally, after $5 \mathrm{~min}, 750 \mu \mathrm{L}$ of sodium hydroxide solution $(1 \mathrm{M} \mathrm{NaOH})$ and $1.4 \mathrm{~mL}$ of distilled water were added to the mixture. The mixture's absorbance was recorded at $510 \mathrm{~nm}$ via a visible spectrophotometer (Novaspec II Visible Spectrophotometer; Pharmacia Biotech). The results were expressed as milligram of quercetin equivalents (QE) per $1 \mathrm{~g}$ of the sample's 


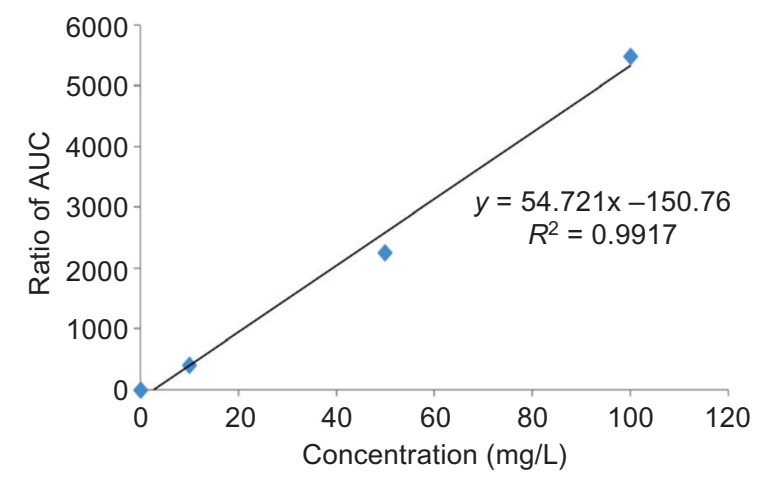

Figure 2. Spiked calibration curve for Quercetin.

dry weight. Figure 2 shows the spiked calibration curve for quercetin as a representative.

\section{Cyanidin-3-glucoside content (Cyd-3-glu)}

The Cyd-3-glu content in the seed coat of each genotype was measured using the $\mathrm{pH}$ difference method with two buffer systems, including potassium chloride $(\mathrm{pH}=1$ and $0.025 \mathrm{~m})$ and sodium carbonate $(\mathrm{pH}=4.5$ and $0.4 \mathrm{~m})$, according to guidelines (Giusti and Wrolstad, 2001) and a $1 \% \mathrm{HCl}$ solvent system in ethanolic at 530 and $700 \mathrm{~nm}$ (Siegelman and Hendricks, 1958).

\section{Antioxidant activity assay by DPPH (2,2-diphenyl-1-picrylhydrazyl)}

The strength of extracts of each genotype in trapping the DPPH free radicals was measured according to the Hatemnia et al. (2014) method at a wavelength of 515 $\mathrm{nm}$. DPPH free radical removal activity, which is an indicator of the antioxidant activity rate of plant extracts, was calculated according to equation 1 :

$$
\operatorname{RSA}(\%)=\frac{\mathrm{A} 0-\mathrm{A} 1}{\mathrm{~A} 0} \times 100
$$

In this regard, A0 is the control absorption, A1 is the absorption sample, and RSA (Radical Scavenging Activity Assay) is the percentage of free radical removal activity. To better evaluate this activity, synthetic antioxidant Butylated Hydroxy Anisole (BHA) was used as a positive control.

\section{Chromatographic separation of phenolic and flavonoid Compounds}

Components using HPLC (high-performance liquid chromatographic) Analysis (Shimadzu, Tokyo, Japan) was used to separate the effective compounds (chlorogenic acid, gallic acid, caffeic acid, $p$-coumaric acid, ferulic acid, rutin, quercetin, and apigenin) in the studied genotypes. The resultant extracts were evaporated to remove ethanol and vacuum-dried under room temperature. The residues were redissolved in ethanol (80\%). The HPLC evaluation procedure used by Lin and Harnly was followed, with some modifications. HPLC was conducted using a Shimadzu chromatographic system (Shimadzu, Tokyo, Japan). The injection volume was $50 \mu \mathrm{L}$, and article chromatograms were acquired at 260 and $330 \mathrm{~nm}$. Solutions of available pure known compounds were chromatographed as external standards. All standards were dissolved in HPLC grade ethanol before injection in the analytical column for analysis. Identification of phenolic and flavonoid compounds of seed coat extracts was performed depending on the retention time (RT) of each one compared with those of pure standards. The results were expressed as milligram per $100 \mathrm{~g}$ of sample dry weight. According to Lin and Harnly (2010), after performing sloping chromatography at a speed of $1 \mathrm{~mm}$ per min, the chromatogram was obtained by HPLC manager software, and then the curves were calculated and interpreted.

\section{The measurement of antibacterial activity}

Standard strains including Pseudomonas aeruginosa (PTCC 1707), Escherichia coli (PTCC 1763), Klebsiella pneumonia (PTCC 1290), and Salmonella typhi (PTCC 1609) as gram-negative bacteria and Staphylococcus aureus (PTCC 1431) as gram-positive bacteria were obtained in the lyophilized form from Scientific and Industrial Research Organization of Iran.

To investigate the antibacterial properties of the extracts, the micro-dilution method was used. The bacterial strains were cultured twice in the Mueller-Hinton agar medium_and then incubated for $24 \mathrm{~h}$ at $37^{\circ} \mathrm{C}$. To obtain a half McFarland concentration $\left(10^{8} \mathrm{CFU} / \mathrm{mL}\right)$, each of the cultured strains was re-cultured in the Mueller-Hinton agar medium_and incubated for $18 \mathrm{~h}$ at $37^{\circ} \mathrm{C}$. Various dilutions of each genotype's extract were prepared in the liquid Mueller-Hinton agar medium_to calculate the minimum inhibitory concentration (MIC). The microbial suspension of half McFarland was then added to each dilution (per $\mathrm{mL}$ of liquid) and incubated for $24 \mathrm{~h}$ at $37^{\circ} \mathrm{C}$. For each genotype, the last dilution in which no turbidity was observed was considered the MIC.

\section{Statistical analysis}

According to a $t$-test procedure, data were analyzed with 3 replicates in each treatment, using SAS statistical software (version 9.1; SAS Institute Inc., Cary, NC, USA). 


\section{Results and Discussion}

\section{Total flavonoid content (TFC)}

Comparing the average TFC between the seed coat extracts (Table 1) showed no significant difference between the studied genotypes, which is not consistent with our previous study results (Karami et al., 2018). In our previous study, seed coat extract of black-seeded genotype (A82) had significantly lower TFC content than white-seeded genotypes. One explanation could be the type of solvent used for the extraction. In our previous study, methanol was used for extraction, while in this study, ethanol was used. Several studies have shown that the type of solvent used to extract plays an important role in determining the plant's extracted polyphenolic content (Skowyra et al., 2014). In the Kermani et al. (2019) study, the TFC index of seed methanolic extract in black sesame seeds was higher than in white seeds, which is probably due to the effect of the species on flavonoid content

\section{Cyanidin-3- glucoside content (Cyd-3-glu)}

The results of Cyd-3-glu measurement in the studied genotypes showed that unlike the black-seeded genotype (A82), the seed coat extract of white-seeded genotype (C111) lacked this compound (Table 1). These results are consistent with the results of our previous study (Karami et al., 2018). However, the concentration of Cyd-3-glu in the methanolic extract was higher than ethanolic extract, which may be related to the extracted solvent's effect. The association between anthocyanin content and seed color has previously been reported in some oilseeds, cereals, and legumes. Choung et al. (2001) compared black, green, and yellow seed soybeans and found that anthocyanins only exist in black seed soybeans, and the green and yellow seed soybeans lack the anthocyanin. On the other hand, the absence of anthocyanin in the seed coat extract of white-seeded safflower genotypes can be attributed to the lack of expression of some genes in biosynthesis pathway flavonoids (Karami et al., 2018).

\section{Antioxidant activity assay by the DPPH method}

The result of the $t$-test analysis indicated that no significant differences between the two genotypes with respect to their antioxidant activity (Table 1 ). Antioxidant activity depends on the number of phenols, flavonoids, and anthocyanins in a plant, and these compounds have a high ability to remove the free radicals. Therefore, genotypes' ability to remove free radicals can be attributed to differences in the secondary metabolites content. As mentioned above, the genotype $\mathrm{C} 111$ with a white seed coat exhibited a similar level of radical scavenging activity compared with the black-seeded genotype A82, despite the absence of Cyd-3-glu in its seed coat. Thus, it seems that other compounds such as phenolics and/or flavonoids possibly contribute to the antioxidant activities of this genotype.

Afterward, the HPLC results confirmed this hypothesis. They revealed that despite the equal concentrations of chlorogenic, $p$-coumaric, and caffeic acid in the two genotypes, it seems that due to the higher concentrations of gallic acid, rutin, ferulic acid, quercetin, and apigenin in the white-seeded genotype C111 (Table 2), the above compounds are highly associated in antioxidant activity and compensate for the absence of Cyd-3-glu in this

Table 1. Total flavonoid content, cyanidin-3-glucoside and antioxidant activity of ethanolic seed coat extract of the studied safflower genotypes.

\begin{tabular}{|c|c|c|c|c|}
\hline Samples & Seed coat color & $\begin{array}{l}\text { Total Flavonoid Content } \\
\text { (mgQUE.g } \text {-1DW) }^{-1} \text {. }\end{array}$ & Antioxidant activity (\%) & $\begin{array}{l}\text { Cyanidin-3 glucoside } \\
\text { (mgcyd-3-glu. } \text { - }^{-1} \mathrm{DW} \text { ) }\end{array}$ \\
\hline A82 & Black & $3.38 \pm 0.13^{\mathrm{a}}$ & $72.26 \pm 2.53^{\mathrm{a}}$ & $13.96 \pm 0.34^{a}$ \\
\hline C111 & White & $3.06 \pm 0.11^{\mathrm{a}}$ & $68.8 \pm 3.05^{\mathrm{a}}$ & $0.00^{b}$ \\
\hline
\end{tabular}

Similar letters indicate no significant difference at the 0.05 level in the column.

DW: dry weight.

Table 2. Polyphenolic compounds identified in ethanolic extract of seed coat extract in the studied safflower genotypes based on HPLC analysis (mg/100 g WD).

\begin{tabular}{lccccccccc} 
Samples & $\begin{array}{c}\text { Seed coat } \\
\text { color }\end{array}$ & $\begin{array}{c}\text { Gallic } \\
\text { acid }\end{array}$ & $\begin{array}{c}\text { Chlorogenic } \\
\text { acid }\end{array}$ & $\begin{array}{c}\text { Caffeic } \\
\text { acid }\end{array}$ & $\begin{array}{c}p \text {-Comaric } \\
\text { acid }\end{array}$ & $\begin{array}{c}\text { Rutin } \\
\text { acid }\end{array}$ & $\begin{array}{c}\text { Ferulic } \\
\text { Quercetin }\end{array}$ & Apigenin \\
\hline \multirow{2}{*}{ A82 } & Back & 0.25 & 1.46 & 6.15 & 6.03 & 7.89 & 4.31 & 2.80 & 4.47 \\
C111 & White & 0.51 & 1.45 & 6.26 & 6.05 & 11.63 & 7.58 & 3.41 & 6.69 \\
\hline
\end{tabular}




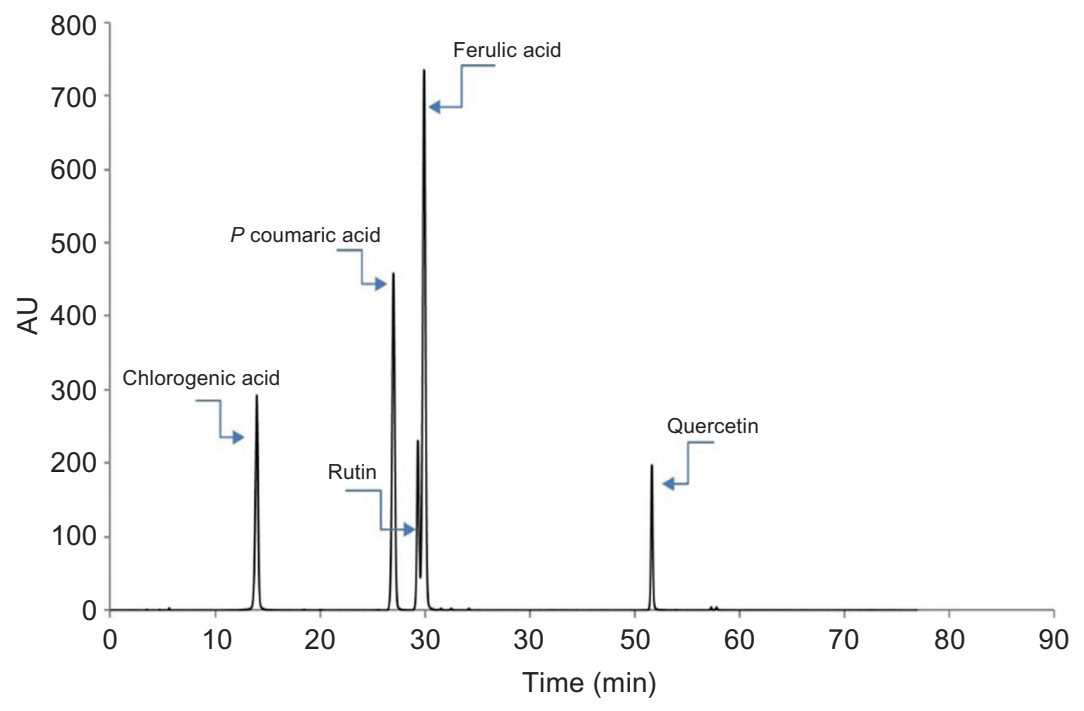

Figure 3. A chromatogram obtained for the polyphenolic compounds.

genotype. An HPLC chromatogram of polyphenolic compounds analyzed in the safflower is shown in Figure 3.

In line with this hypothesis, Salami et al. (2016) reported that the content of total phenol and phenolic compounds compared to the TFC and flavonoid compounds showed more free radical removal activity in different fenugreek genotypes (Foeniculum vulgare). The present study results were different from the previous study (Karami et al., 2018). As in our previous study, white-seed safflower genotypes showed a lower ability to remove free radicals than black-seeded genotypes. One explanation for these differences detected between the two studies is the difference in the type of solvent used for extraction. In a study by Shen et al. (2009), black-seeded rice indicated higher free radical removal potency levels than other rice colors (Shen et al., 2009). Kermani et al. (2019) also showed that black sesame had higher antioxidant properties than white sesame.

\section{Antibacterial activity}

The results of the antibacterial effect of different genotype seed coat extracts on the studied bacteria are given in Table 3. There was no significant difference in the MIC index between the two genotypes. The results also exhibited that $P$. aeruginosa and $K$. pneumonia bacteria's susceptibility to the seed coat extracts of both genotypes was much higher than other studied bacteria. Sabah et al. (2015) reported that the phenolic extract of safflower oil had an excellent inhibitory effect on $S$. aureus and $E$. coli bacteria. In another study, Abdel Moneim et al. (2018) showed that safflower methanolic and water extracts have a high potency in inhibiting the growth of S. aureus, E. coli, P. aeruginosa, and $K$. pneumonia bacteria, and their inhibitory power varies depending on the type of bacteria (Abdel Moneim et al., 2018). The highest inhibitory effect was observed on K. pneumonia, which is consistent with the results of our study. Qazi et al. (2013) investigated the bacteria isolated from clinical samples ( $E$. Coli, B. subtilis, S. agalactiae) and showed that safflower ethanolic flower extract has lower antibacterial effects at low concentrations and the antibacterial effects also depend on the type of bacteria. In another study, Salami et al. (2016) reported a moderate antibacterial effect of leaf extract of fenugreek genotypes (Foeniculum vulgare) on S. aureus, E. Coli, and P. aeruginosa bacteria. The antibacterial activity of plant extracts is more related to the presence of polyphenolic compounds. These compounds inhibit bacteria growth through various mechanisms such as cell wall destruction, cell membrane destruction, and intracellular bacterial matrix destruction. Bacterial type, cell wall structure, and quantitative and qualitative content of extract compounds are among the determinants of the extract's antibacterial potency (Mazzei et al., 2020).

Table 3. Minimum inhibitory concentration (MIC) of ethanolic extract of seed coat in the studied safflower genotypes (mg/mL).

\begin{tabular}{lcccccc} 
Samples & Seed coat color & E. coli & K. pneumonia & S. typhi & St. aureus & P. aeruginosa \\
\hline A82 & Black & 500 & 125 & 500 & 500 & 250 \\
C111 & White & 500 & 125 & 500 & 500 & 250 \\
\hline
\end{tabular}


Therefore, the observed difference in the results of different studies could be related to these factors.

\section{Conclusion}

The safflower genotype A82 with a unique seed color pattern (black) is known as a novel breeding line and a promising safflower fly-resistant safflower genotype; however, a limited assay was only performed on this novel breeding line. Thus, the present study aimed to investigate secondary metabolites' content and also antioxidant and antibacterial activities of ethanolic seed coat extract of two safflower genotypes (genotype C111 and A82) with contrasting seed coat colors. Based on the results obtained, the ethanolic extract of the safflower seed coat has appropriate antioxidant and antibacterial properties. Also, despite the differences detected in polyphenolic compounds of black-seeded genotypes (A82) and white-seeded genotypes (C111), there was no significant difference between them in antibacterial and antioxidant properties. On the other hand, the results of ethanolic seed coat extract (the present study) with methanolic seed coat extract (previous studies) showed that the type of solvent used for extraction has a significant effect on the quantity and quality of polyphenolic compounds in each genotype, and this can affect the antioxidant properties.

\section{Acknowledgments}

The authors are grateful to Professor Sabzalian M.R. for providing safflower varieties (specimen_voucher = personal collection: Mohammad R. Sabzalian).

\section{Conflict of interest}

The authors declare that there are no conflicts of interest.

\section{Ethical approval}

This study does not involve any human or animal testing.

\section{References}

Abdel Moneim, E., Sherif, M., Ahmed, A., Mohanad, A. and Vajid, N., 2018. Evaluation of antimicrobial activity of safflower (Carthamus tinctorius) and its synergistic effect with antibiotic. EC Microbiology 14: 160-166.

Akond, A., Khandaker, L., Berthold, J., Gates, L., Peters, K., Delong, H., et al. 2011. Anthocyanin, total polyphenols and antioxidant activity of common bean. American Journal of Food Technology 6: 385-394. https://doi.org/10.3923/ ajft.2011.385.394

Brizzolari, A., Brandolini, A., Glorio-Paulet, P. and Hidalgo, A., 2019. Antioxidant capacity and heat damage of powder products from South American plants with functional properties. Italian Journal of Food Science 31: 731-748. https://doi.org/10.14674// IJFS-1521.SAFF

Choi, S.H., Lee, A.Y., Park, C.H., Shin, Y.S. and Cho, E.J., 2018. Protective effect of Carthamus tinctorius L. seed on oxidative stress and cognitive impairment induced by chronic alcohol consumption in mice. Food Science and Biotechnology 27: 1475-1484. https://doi.org/10.1007/s10068-018-0472-4

Choung, M. G., Baek, I. Y., Kang, S. T., Han, W. Y., Shin, D. C., Moon, H. P., et al. 2001. Isolation and determination of anthocyanins in seed coats of black soybean (Glycine max (L.) Merr.). Journal of agricultural and food chemistry 49: 5848-5851. https://doi.org/10.1021/jf010550w

Fang, S., Yang, W., Chu, X., Shang, X., She, C. and Fu, X., 2011. Provenance and temporal variations in selected flavonoids in leaves of Cyclocarya paliurus. Food Chemistry 124: 1382-1386. https://doi.org/10.1016/j.foodchem.2010.07.095

Giusti, M.M. and Wrolstad, R.E., 2001. Characterization and measurement of anthocyanins by UV-visible spectroscopy. Current Protocols in Food Analytical Chemistry 1: F1-2. 2.1-F1. 2.13. https://doi.org/10.1002/0471142913.faf0102s00

Güner, A., Kızılşahin, S., Nalbantsoy, A. and Yavaşoğlu, N.Ü.K., 2020. Apoptosis-inducing activity of safflower (Carthamus tinctorius L.) seed oil in lung, colorectal and cervix cancer cells. Biologia 75: 1465-1471 (2020). https://doi.org/10.2478/ s11756- 020-00458-2

Hatamnia, A.A., Abbaspour, N. and Darvishzadeh, R., 2014. Antioxidant activity and phenolic profile of different parts of Bene (Pistacia atlantica subsp. kurdica) fruits. Food chemistry 145: 306-311. https://doi.org/10.1016/j.foodchem.2013.08.031

Kanu, P.J., 2011. Biochemical analysis of black and white sesame seeds from China. American Journal of Biochemistry and Molecular Biology Am J Biochem Mol Biol 11: 145-157. https:// doi.org/10.3923/ajbmb.2011.145.157

Karami, S., Sabzalian, M.R. and Rahimmalek, M., 2018. Seed polyphenolic profile, antioxidative activity, and fatty acids composition of wild and cultivated Carthamus species. Chemistry \& Biodiversity 15: e17005621-11. https://doi.org/10.1002/ cbdv. 201700562

Karami, S., Sabzalian, M.R., Khorsandi, L. and Rahimmalek, M., 2017a. Safety assessment of a new pigmented safflower seed coat (A82) by a feeding study on rat. Brazilian Archives of Biology and Technology 60: 1-10. https://doi. org/10.1590/1678-4324-2017160564

Karami, S., Sabzalian, M.R., Rahimmalek, M., Saeidi, G. and Ghasemi, S., 2017b. Interaction of seed coat color and seed hardness: Aan effective relationship which can be exploited to enhance resistance to the safflower fly (Acanthiophilus helianthi) in Carthamus spp. Crop Protection 98: 267-275. https://doi. org/10.1016/j.cropro.2017.04.006

Kermani, S. G., Saeidi, G., Sabzalian, M. R., and Gianinetti, A. 2019. Drought stress influenced sesamin and sesamolin content and 
polyphenolic components in sesame (Sesamum indicum L.) populations with contrasting seed coat colors. Food chemistry 289: 360-368. https://doi.org/10.1016/j.foodchem.2019.03.004.

Lin, L.-Z. and Harnly, J.M., 2010. Identification of the phenolic components of chrysanthemum flower (Chrysanthemum morifolium Ramat). Food Chemistry 120: 319-326. https://doi. org/10.1016/j.foodchem.2009.09.083

Mazzei, R., Leonti, M., Spadafora, S., Patitucci, A. and Tagarelli, G., 2020. A review of the antimicrobial potential of herbal drugs used in popular Italian medicine (1850s-1950s) to treat bacterial skin diseases. Journal of Ethnopharmacology 250: 112443. https://doi.org/10.1016/j.jep.2019.112443

Nimrouzi, M., Ruyvaran, M., Zamani, A., Nasiri, K. and Akbari, A., 2020. Oil and extract of safflower seed improve fructose induced metabolic syndrome through modulating the homeostasis of trace elements, TNF- $\alpha$, and fatty acids metabolism. Journal of Ethnopharmacology 254: 112721. https://doi.org/10.1016/j. jep.2020.112721

Palacios-Rojas, N., McCulley, L., Kaeppler, M., Titcomb, T.J., Gunaratna, N.S., Lopez-Ridaura, S., et al., 2020. Mining maize diversity and improving its nutritional aspects within agro-food systems. Comprehensive Reviews in Food Science and Food Safety 19: 1809-1834. https://doi.org/10.1111/1541-4337.12552

Qazi, N., Alam Khan, R., Faiz Kazi, Y., Kumar, P. and Rizwani, G., 2013. Antibacterial activity of Carthamus tinctorius L. against bacterial isolates. Journal of Antimicrobials 128: 172-176.

Rezig, L., Sadaa, M., Trabelsi, N., Tammar, S., Limam, H., Rebey, I.B., et al., 2019. Chemical composition, antioxidant and antimicrobial activities of Aloysia Triphylla L. essential oils and methanolic extract. Italian Journal of Food Science 31:556-572. https:// doi.org/10.14674/IJFS-1373

Sabah, F.S. and Saleh, A.A., 2015. Evaluation of antibacterial activity of flavonoid and oil extracts from safflower (Carthamus tinctorius L). Journal of Natural Sciences Research 5: 41-45.

Sabzalian, M.R., Saeidi, G. and Mirlohi, A., 2008. Oil content and fatty acid composition in seeds of three safflower species. Journal of the American Oil Chemists' Chemists' Society 85: 717-721. https://doi.org/10.1007/s11746-008-1254-6

Sabzalian, M.R., Saeidi, G., Mirlohi, A. and Hatami, B., 2010. Wild safflower species (Carthamus oxyacanthus): a possible source of resistance to the safflower fly (Acanthiophilus helianthi). Crop Protection 29: 550-555. https://doi.org/10.1016/j. cropro.2009.12.013
Salami, M., Rahimmalek, M., Ehtemam, M. H., Szumny, A., Fabian, S., and Matkowski, A. 2016. Essential oil composition, antimicrobial activity and anatomical characteristics of Foeniculum vulgare Mill. fruits from different regions of Iran. Journal of Essential Oil Bearing Plants 19: 1614-1626. https:// doi.org/10.1080/0972060X.2015.1117951

Shen, Y., Jin, L., Xiao, P., Lu, Y. and Bao, J., 2009. Total phenolics, flavonoids, antioxidant capacity in rice grain and their relations to grain color, size and weight. Journal of Cereal Science 49: 106-111. https://doi.org/10.1016/j.jcs.2008.07.010

Siegelman, H. and Hendricks, S., 1958. Photocontrol of anthocyanin synthesis in apple skin. Plant Physiology 33: 185. https://doi. org/10.1104/pp.33.3.185

Skowyra, M., Gallego, M.G., Segovia, F. and Almajano, M.P., 2014. Antioxidant properties of Artemisia annua extracts in model food emulsions. Antioxidants 3: 116-128. https://doi. org/10.3390/antiox3010116

Thaddi, B. and Nallamilli, M., 2014. Estimation of total bioactive compounds in pigmented and non-pigmented genotypes of Sorghum (Sorghum bicolor (L.) Moench). International Journal of Advanced Research in Science and Technology Int J Adv Res Sci Technol 3: 86-92.

Tohidi, B., Rahimmalek, M., and Arzani, A. 2017. Essential oil composition, total phenolic, flavonoid contents, and antioxidant activity of Thymus species collected from different regions of Iran. Food chemistry 220: 153-161. https://doi.org/10.1016/j. foodchem.2016.09.203

Turgumbayeva, A., Ustenova, G., Datkhayev, U., Rahimov, K., Abramavicius, S., Tunaityte, A., et al., 2020. Safflower (Carthamus Tinctorius tinctorius L.) a potential source of drugs against Cryptococcal infections, malaria and Leishmaniasis. Phyton 89: 137. https://doi.org/10.32604/phyton.2020.07665

Yu, S. Y., Lee, Y. J., Kim, J. D., Kang, S. N., Lee, S. K., Jang, J. Y., et al., 2013. Phenolic composition, antioxidant activity and anti-adipogenic effect of hot water extract from safflower (Carthamus tinctorius L.) seed. Nutrients 5: 4894-4907. https:// doi.org/10.3390/nu5124894

Zuniga-Salcedo, M., Ulloa, J., Bautista-Rosales, P.U., Rosas-Ulloa, P., Ramírez-Ramíez, J., Silva-Carrillo, Y., et al., 2019. Effect of ultrasound treatment on physicochemical, functional, and nutritional properties of a safflower (Carthamus tinctorius L.) protein isolate Italian Journal of Food Science 31: 592-603. https://doi. org/10.14674/IJFS-1440 